\title{
German poll could change research goals
}

[MUNICH] With Germany's federal election looming, parliament has approved a 3.4 per cent, DM500 million ( $\$ 295$ million) increase in next year's education and research budget, as proposed by minister Jürgen Rüttgers.

But the public seems unimpressed. Polls indicate that the current Christian Democrat/Free Democrat coalition government may not be running the country after the elections, due on 27 September.

A late turnaround remains possible, but most money at the moment is on either a Social Democrat/Green coalition or a 'grand coalition' of Christian Democrats (CDU) and Social Democrats (SPD).

For scientists a grand coalition would mean little change, as both major parties essentially share a platform on research. Both pledge at least to maintain current levels of funding for basic research organizations such as the Max Planck Society and the Deutsche Forschungsgemeinschaft (DFG), Germany's main grant-giving body. Both are committed to competition and industrial relevance in research. Both say genetic and information technologies are priorities, and agree that medium-sized enterprises should be encouraged to conduct more research.

One main difference is that the SPD wants to double the budget for science and education in the next five years. But most scientists take this promise with a pinch of salt. "There certainly is a need for a change, but I doubt that the SPD would keep its financial promises," says Siegfried Bethke, head of particle physics at the University of Aachen.

Rüttgers promised to increase the science budget when his appointment as 'minister of the future' was announced in 1994 amid great fanfare. In fact, the budget remains at much same level and has fallen around five per cent in real terms.

The SPD wants to move responsibility for research from the education ministry to the economics ministry, which would be run by CompuNet founder Jost Stollmann, 43, a businessman with no political experience.

The research portfolio would be given to Edelgard Bulmahn, a 47-year old political sciences graduate with 12 years' experience on the parliamentary committee for education and research. Bulmahn says that one of her goals is to work closely with other ministries. "The SPD wants research policy to be fully integrated with other government policies, relating for example to tax, environment and transport," she says.

Prospects of a coalition including the Green Party sends a wave of fear through the scientific community. Although the Greens have softened their stance on biotechnological research (see Nature 392, 213; 1998), their election programme states that the party "generally rejects genetic engineering".

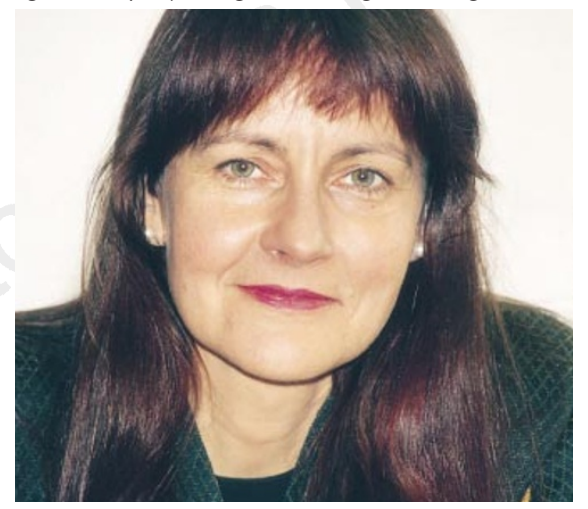

Bulmahn: SPD wants research integrated with policies on tax, environment and transport.

\section{Plan to pool part of Europe's science cash}

[MUNICH] The heads of Europe's national research councils, who meet regularly as a group called the Eurohorcs, are to consider a proposal to pool part of their funds for reallocation to European-level programmes.

The idea has been put forward by Reinder van Duinen, president of the Dutch research organization NWO. It is aimed at promoting research in areas not supported through the European Commission in Brussels, and would probably be run by the European Science Foundation (ESF). Specific ideas include phase 1 clinical trials and some areas of social science.

Van Duinen says he is "encouraged" by the response he has received to his proposal, which emphasizes the importance of a light, non-bureaucratic structure.

Ernst Winnacker, president of the Deutsche Forschungsgemeinschaft (DFG), is enthusiastic. But he warns that the legal implications of transferring money allocated for national research to an international body could be a stumbling block in some countries.

Richard Brook, head of both Eurohorcs and the UK Engineering and Physical Sciences Research Council, is cooler. "There are already mechanisms for setting up international collaborations between national research organizations through biand multilateral agreement," he says.

Van Duinen says such collaborations take place in an ad hoc way — "the wheel is constantly being reinvented". He adds: "We need a system which has a memory of the basic organization of collaborations."

The Eurohorcs will discuss the proposal at their next meeting, to be held in Oslo in October.

A. A.
The Greens want to tighten Germany's genetic-engineering laws and ban field trials of genetically modified crops. Manuel Kiper, spokesman for the Green's parliamentary group on research policy, calls field trials "a game of hazard with evolution". Both policies would cause conflict with their potential coalition partner, as the SPD has a much less hostile attitude to genetic engineering.

Kiper says that, although the Greens would respect existing treaties, they would want to start negotiations immediately to stop Germany's involvement in projects like the international fusion project ITER, the International Space Station (ISS) and, of course, the nuclear energy programme.

The SPD is broadly sympathetic, but hopes that international support for ITER and ISS will fade with time and calls for Germany's 19 nuclear power stations laws to be shut down gradually over the next 30 years.

The Greens want to promote environmental research, alternative energy research and complementary medicine. They also want to bring high-profile private environment research institutes - such as the Eco Institute and the Institute for Social Ecology - into the state funding system, with government providing 25 per cent of the institutional funding. The SPD supports this plan.

As a junior coalition partner, the Greens would be allocated at least two ministries. Their first priority would be to win the environment ministry. One of their second choices would be research, although the SPD is against this idea.

Ernst-Ludwig Winnacker, president of the DFG and long-time lobbyist for genetic engineering in Germany, says that scientists are "quite worried about the possibility of a coalition with the Greens". Having the Greens in government would be quite detrimental to research, he says.

Not all scientists share his opinion, however. Bethke, for example, says he has "a very good feeling” about the Greens' support for basic physics research, such as the planned new linear accelerator in Hamburg.

Whoever takes over research and education after the election will face two major unresolved problems, which no party has addressed in its election campaign. The first is the chronic underspending on university building and large equipment. According to the Wissenschaftsrat, Germany's science council, the annual budget for this needs to be increased by at least DM1 billion to meet what it regards as urgent needs.

The second problem is east Germany. Although more than DM20 billion has been invested in its research infrastructure since 1990, it still lags behind the west, which still has four times more researchers per head of population. QuirinSchiermeier \& Alison Abbott 